\title{
Concepts and items in measuring social harm from drinking
}

\author{
Robin Room* \\ Centre for Social Research on Alcohol and Drugs, Stockholm University, Sveaplan, S-106 91 Stockholm, Sweden
}

\begin{abstract}
Social epidemiological traditions of asking about problems related to drinking are considered. The issue of the attribution of the problem to drinking, and variations in formulations concerning this, are discussed. Social problems from drinking are inherently properties of social interactions, so that they are composed both of behaviour deemed problematic and of a reaction by another. Most items measuring social harm asked of the drinker him/herself are concerned with major social roles, and problems in the particular life area of the role (work, family, friendships, etc.). Some ask the respondent to attribute the problems to alcohol, some ask about others' attributions to alcohol, and some ask about "objective" problem indicators, although these usually have the respondent's attribution to drinking built in. The possibility of a more systematic way of covering different aspects of interactional problems, as reported by the drinker, is considered. Traditions of questioning the person on the other side of the interaction - i.e., items about others' troubles with drinking, and the effect of these on the respondent - are also discussed, and possibilities for bringing questions asked of the drinker and questions asked of interacting others into the same frame are considered. (C) 2001 Elsevier Science Inc. All rights reserved.
\end{abstract}

Keywords: Alcohol problems; Social harm; Social interaction; Attribution; Role failure

\section{Introduction}

Social policy about alcohol has largely been driven, both now and in the past, by concerns about social and casualty harms from drinking (Room, 1996a), yet there is little consensus on methods of measuring social harms from drinking in population surveys. This contrasts with what appears to be growing consensus both about how to measure patterns and amounts of drinking (Room, 2000) and about measures of alcohol disorders in psychiatric epidemiology.

* Tel.: +46-8-674-7047; fax: +46-8-674-7686.

E-mail address: robin.room@sorad.su.se (R. Room) 
This paper considers some of the traditions of measurement of social harm in population surveys, aiming to further the development of common approaches on an international basis.

Social harms from drinking are inherently interactional (Room, 1998). For the social harm to be recognized as occurring, there must be not only a drinking behaviour that is seen as problematic, but also a reaction by someone other than the drinker. The harm may occur to the drinker, or to some other particular person. On the other hand, the harm may not happen to anyone in particular, but may be located at an aggregate level, e.g., in diminished work productivity in an office as a whole.

The primary emphasis in surveys of problems related to drinking has been on characteristics and behaviour of the respondent. This has been combined with a methodological individualism in sampling designs, whereby one respondent is chosen per household to minimize crosscontamination. Often, little attention is paid to social interactions and contexts. However, samples and questions have sometimes been designed to get information from both sides of an interaction (Room, 1989a). Another option for looking beyond the individual level is to analyze survey data in conjunction with census or other aggregate statistics, or (when respondents to a survey are clustered) to aggregate their responses (Cahalan \& Room, 1974). Work along these lines is, however, beyond the scope of the present paper.

We will, however, consider one further option in looking beyond what the drinker can tell us about problems related to his or her drinking. This is the strategy of asking respondents about how the drinking of others in general has impinged on them.

For the present purposes, "social harm" is defined as perceived misperformance or failure to perform in major social roles - as a family member, as a worker, as a friend or neighbour, or in terms of public demeanour. The failure to perform properly may be momentary, in the event, or it may be continuing and cumulative. Given the interactional nature of social harm, there may be substantial disagreement about whether there is, indeed, any failure to perform properly. One person's idea of "having a little fun" may be another's social harm.

We will thus include within consideration alcohol-related problems with the family, with friends, with the job, and with the police. It is appropriate, too, to include behaviours that others are likely to see as problematic in a consideration of alcohol-related social harm. So we include within our scope, also, such aspects as belligerence while drinking, alcohol-related work absenteeism, and financial problems from drinking.

We will generally exclude from consideration health and casualty problems, although they are often lumped in the same category with social harm. Also excluded are aspects of the respondent's own mental state concerning his or her drinking behaviour, although items in this domain are likely often to reflect an internalization of others' reactions (e.g., such items as "I have felt guilty or ashamed because of my drinking"). However, since research traditions have generally dealt with the broader frame of "drinking-related problems" in general, our discussions of these traditions are inclusive.

\section{Traditions of asking about adverse consequences of drinking}

Asking general-population respondents about adverse consequences of their own drinking begins with Straus and Bacon's study of college students (Straus \& Bacon, 1953), and has 
continued for the intervening half century. Studies have varied greatly in the number of items asked concerning drinking problems, but not very much in terms of the areas about which questions are asked. Usually, respondents are asked about adverse reactions of others to their drinking. Questions on casualties and physical health problems related to drinking are

Table 1

Social harm items in the Jellinek (1946) questionnaires

A. In the AA Grapevine questionnaire: At what age did you first...

8. Act in a financially extravagant manner while drinking? (Example: Cashing a check for more than you need and spending all of it without getting anything for it except a hangover)

17. Commit antisocial acts while drinking? (Example: Pick a fight with a stranger in a saloon for no justifiable reason)

18. Realize that your friends or family were trying to prevent or discourage your drinking?

25. Lose a friend as the result of drinking?

26. Lose working time as the result of drinking?

27. Lose a job as a result of drinking?

28. Lose advancement in a job as the result of drinking?

B. In Jellinek's proposed revised questionnaire (male form):

22. If at any time your wife or family supported you, state: from age to age

23. If at any time you had to turn over the conduct of your finances to your wife or to the family members, state: from age to age

24. Your age when your wife first reproached you because of your drinking:

25. Your age when your wife's family reproached you because of your drinking:

26. Your age when wife began to reproach you for humiliating her by your drinking:

27. Your age when wife began to reproach you for neglecting the finances:

28. Your age when your wife began to reproach you for neglect of children, bad example, etc.:

29. Your age when your wife began to show signs of jealousy:

30. Your age when wife or other members of your immediate household began changing their habits because of your drinking (example: going out more frequently or less frequently; joining clubs; begin inviting people to the house or stop inviting people to the house; begin to take part in civic activities or stop taking part in civic activities, etc.):

34. Your age when you began losing time [from work] because of drinking:

35. Your age when you first walked out on jobs:

36. Your age when you first lost job because of drinking:

37. Your age when you first lost advancement because of drinking:

39. Your age when you were unemployed for periods of more than 3 months:

77. Age when during drinking you started acting in an aggressive, belligerent or malicious way or committed acts dangerous to yourself or others:

78. Age when you got into trouble because of drunk driving:

79. Age when you began convincing yourself that any neglect to which you may have exposed your family was justified because your drinking was necessary for you or because "it was coming to them":

80. Age when you began feeling that for your special case your family and the world in general ought to show more consideration:

81. Age when you began suspecting that people were feeling contempt for you, or in the best case, pity:

82. Age when you began to feel that if people were not "sitting on you" because of your drinking you would be capable of considerable accomplishments:

83. Age when you began to have ideas of jealousy concerning your wife or girl friend:

90. Age when you sought or accepted the services of an intermediary to straighten out matters with your family, friends, or employer: 
Table 2

Social harm problem scores and items, 1969 national sample of males (Cahalan and Room, 1974)

Problems with wife:

60. During the last 3 years, did your wife show any concern about your drinking?

60a. [if yes:] During the last 3 years, did she ever get angry about it? [if yes] what happened — did she get angry without threatening to leave or did she threaten to leave or did she actually leave because of your drinking?

42d. Was there [a time in the last 3 years] when you felt your drinking had a harmful effect on: your marriage or home life?

11. My wife indicated I should cut down on my drinking.

Step 4: wife actually left;

Step 3: wife threatened to leave;

Step 2: wife became angry, or respondent reports drinking has been harmful to his marriage or home life;

Step 1: wife showed concern over respondent's drinking, or indicated he should cut down.

Problems with relatives:

13. My drinking was very displeasing to a relative (other than my wife)

12. Some other relative [not my wife] indicated I should cut down on my drinking

Step 2: drinking very displeasing to relative;

Step 1: relative indicated respondent should cut down

Problem with friends or neighbors:

15. My drinking was involved in losing a friendship or drifting apart from a friend

14. Friends indicated I should cut down on my drinking

16. Neighbors indicated I should cut down on drinking

42a. Was there [a time in the last 3 years] when you felt your drinking had a harmful effect on: your friendships and social life.

Step 4: drinking involved in losing a friendship

Step 2: drinking harmful to friendships, or (friends and neighbors said should cut down)

Step 1: friends or neighbors said should cut down

Job problems:

19. Lost a job, or nearly lost one, because of drinking

20. Drinking led to my quitting a job

21. Drinking may have hurt my chances for promotion or raises or better jobs

17. People at work indicated I should cut down on drinking

18. Have gotten high or tight while on the job

10. Stayed away from work because of a hangover

42e. Was there [a time in the last 3 years] when you felt your drinking had a harmful effect on: your work and employment opportunities

Step 4: item 19 or 20

Step 3: any two of: $21,17,42 \mathrm{e}$

Step 2: any one of: $21,17,42 \mathrm{e}$

Step 1: item 18 or 10

Police problems:

28. Had trouble with the law about driving after drinking

29. Had trouble with the law about drinking, when driving was not involved

27. A policeman questioned me or warned me because of my drinking

Step 4: both 28 and 29 . 
Table 2 (continued)

Step 2: one of 28 or 29

Step 1: item 27

Belligerence:

7. Felt aggressive or cross

8. Got into a fight

9. Got into a heated argument

Step 2: "yes" on all three items

Step 1: "yes" on any two.

Financial problems:

26. Spent money on drinks which was needed for essentials like food, clothing, or payments

25. Spent too much money on drinks, or after drinking

42f. Was there [a time in the last 3 years] when you felt your drinking had a harmful effect on: your

financial position

Step 4: item 26

Step 2: item $42 \mathrm{f}$

Step 1: item 25

Social consequences score:

Constructed by adding together the face value of the steps for wife, relatives, friends/neighbors, job and police problems. A score of $3+$ was treated as "high problems" (14\%), a score of $1+$ as "minimal severity problems"'(45\%).

Asked of a U.S. national sample of males aged 21-59. Most of these items were asked in a series (Question 45 ) on "experiences that many people have reported in connection with drinking," both for the last 3 years and for before 3 years ago. Questions 42 and 60 were asked separately.

Respondents were assigned to steps hierarchically; e.g., those qualifying for both step 4 and step 2 on a score were assigned to step 4 .

commonly included. Respondents are also often asked about problematic drinking comportment: arguments or fights while drinking, drinking-driving, going to work with a hangover. Also asked in one survey or another are a wide variety of drinking-related behaviours or occurrences considered symptomatic of addiction: such items as use of alcohol for coping, drinking to relieve withdrawal, gulping drinks when no one is looking, and drinking longer or more than intended. Many of these items date back to the Grapevine survey constructed by members of Alcoholics Anonymous and analyzed by Jellinek (1946) in terms of phases in the natural history of alcoholism (Table 1 shows the social harm items in this survey and in Jellinek's proposed revision of it).

Table 2 illustrates the development from this of a tradition of social epidemiology by Genevieve Knupfer (1967) and associates, while Table 3 shows 27 items related to social harm from a set of 50 items developed for use in Project MATCH for use in clinical populations (Miller, Tonigan, \& Longabaugh, 1995). The Drinker Inventory of Consequences (DrInC), which divides its inventory of items into five domains, including "interpersonal" and "social responsibility," has also been used in a small sample of social drinkers (Giancola, Zeichner, Yarnell, \& Dickson, 1996). While surveys with problem items across this kind of range have perhaps been most common in the United States, similar lists of "types of 
Table 3

Social harm items in the Drinker Inventory of Consequences (DrInC) (Miller et al., 1995)

"Here are a number of events that drinkers sometimes experience... Indicate how often each one has happened to you DURING THE PAST THREE MONTHS" - never; once or a few times; once or twice a week; daily or almost every day. There are 50 items in the DrInC.

3. I have missed days of work or school because of my drinking

4. My family or friends have worried or complained about my drinking

6. The quality of my work has suffered because of my drinking

7. My ability to be a good parent has been harmed by my drinking

9. I have driven a motor vehicle after having three or more drinks

14. I have failed to do what is expected of me because of my drinking

17. While drinking, I have said or done embarrassing things

19. I have taken foolish risks when I have been drinking

20. I have gotten into trouble because of drinking

21. While drinking, I have said harsh or cruel things to someone

22. When drinking, I have done impulsive things that I regretted later

23. I have gotten into a physical fight while drinking

26. I have had money problems because of drinking

27. My marriage or love relationship has been harmed by my drinking

30. My family has been hurt by my drinking

31. A friendship or close relationship has been damaged by my drinking

34. I have lost interest in activities and hobbies because of my drinking

35. When drinking, my social life has become more enjoyable

39. My drinking has damaged my social life, popularity, or reputation

40. I have spent too much or lost a lot of money because of my drinking

41. I have been arrested for driving under the influence of alcohol

42. I have had trouble with the law (other than driving while intoxicated) because of my drinking

43. I have lost a marriage or close love relationship because of my drinking

44. I have been suspended/fired from or left a job or school because of my drinking

46. I have lost a friend because of my drinking

49. While drinking or intoxicated, I have injured someone else

50. I have broken things or damaged property while drinking or intoxicated

experiences related to drinking" can be found in studies elsewhere, for instance, in Nordic surveys (Mäkelä, 1981).

A new kind of item entered into use as psychiatric epidemiology became more involved in measuring alcohol problems. In constructing questionnaire items, survey researchers usually try to keep items as simple as possible, and avoid "double-barreled" questions. The criteria for the psychiatric diagnoses in the field, however, often deliberately combine different conceptual areas into the same criterion. A criterion like "continued drinking despite knowledge of adverse consequences," for instance, combines behaviour (continued drinking), cognition (knowledge of...) and the occurrence of adverse consequences. In seeking to operationalize such criteria, those constructing questionnaires have felt forced to construct what survey researchers term "portmanteau items" - items incorporating two or more implied questions. Conventional survey research wisdom is that such items are difficult to understand and to answer, and responses to them are difficult to interpret. As an example of the psychiatric epidemiology 
Table 4

Social harm items in AUDADIS (August 1997 version) (see Stinson et al., 1998, Exhibit 3)

This questionnaire includes 29 items on "experiences that many people have reported in connection with their drinking," asked on a lifetime and a last-12-months basis, with a series of follow-up questions about timing, frequency and concurrence of groups of items. The items are designed to measure the alcohol-dependence and alcohol-abuse criteria in DSM-IV. Items 12 and 13 are for an "alcohol dependence" criterion, the others below for "alcohol abuse."

12. Give up or cut down on activities that were important to you in order to drink - like work, school, or associating with friends or relatives

13. Give up or cut down on activities that you were interested in or that gave you pleasure in order to drink

16. Have a period when your drinking or being sick from drinking often interfered with taking care of your home or family

17. Have job or school troubles because of your drinking or being sick from drinking — like missing too much work, not doing you work well, being demoted or losing a job, or being suspended, expelled, or dropping out of school

18. Often drive a car, motorcycle, truck, boat, or other vehicle after having too much to drink

20. Continue to drink even though you knew it was causing you trouble with your family or friends

21. Get into physical fights while drinking or right after drinking

22. Get arrested or held at a police station because of your drinking

tradition, items involving social harm from a well-developed instrument are listed in Table 4 (Stinson et al., 1998).

Table 5

Reactions from others and to others concerning drinking, 1987/89 Contra Costa County Survey (Room, 1989b)

116. A. Now some questions about other people's reactions to your drinking. Have any of your friends, relatives, or acquaintances ever said anything about your drinking or suggested that you cut down?

B. (if yes:) Who said anything about your drinking. (I don't need names, just the relationship of each person to you.) Who else?

C. (for each person:) Did this happen in the last 12 months?

D. Did (person) suggest that you get help for an alcohol problem in the last 12 months?

119. A. How about the drinking of others around you and your reactions to that: In the last 12 months, have you been concerned about or worried about the drinking of any of your friends, relatives, of acquaintances?

120. A. (if yes:) Which of the people on this card were you concerned or worried about?

B. Have you said anything about his/her drinking in the last 12 months?

C. Did you suggest that (person) get help for his/her alcohol problem in the last 12 months?

[relationships, used for both series of questions:]

Husband or wife

Significant other/spouse equivalent

Mother

Father

Brother

Sister

Son

Daughter

Other relative

Friend or acquaintance

Someone else 
Table 6

Criminal victimization and behavior items, 1990 US national survey, Alcohol Research Group, Berkeley (Scott et al., 1999)

Victimization

78. Now I have some questions about unpleasant experiences you may have had. Since you were age $12 \ldots$

79. [If yes] In what year did that happen most recently?

80. Thinking about the most recent time, had the person who did this been drinking?

81. Had you been drinking?

a. Did anyone take a car or motor vehicle without permission that belonged to you or your family?

b. Were you injured or your car or property damaged by a drinking driver?

c. Did anyone illegally enter your car or your house?

d. Did anyone beat you up, attack you, or hit you with something?

e. Did anyone take something from you by force or threat of force?

f. Did anyone force you to have sex with them?

Criminal behavior

82. Many people have done things in their lives for which they could be arrested. Please tell me whether you've ever done each of the following - whether or not you were caught for doing it. Since you were age 12 , have you ever. .

83. [if yes] In what year did that happen most recently?

84. Had you been drinking the most recent time this happened?

85. [for $\mathrm{g}, \mathrm{h}, \mathrm{i}$ ] Had the person to whom this happened been drinking the most recent time it happened?

a. taken a car or other motor vehicle that didn't belong to someone in your family, without permission of the owner?

b. found yourself drunk in a public place?

c. driven a car when you had drunk enough to be in trouble if the police had stopped you?

d. illegally got into a car, house, or a building and taken something?

e. taken something from a store without paying for it?

f. sold drugs illegally?

g. beaten someone up, attacked someone, or hit them with something?

h. taken something from someone by using force or threat of force?

i. forced someone else to have sex with you?

Questions about drinking problems in early drinking surveys were often phrased in terms of lifetime occurrence - "did this ever" occur? Such a phrasing yielded a maximum of positive responses and also reflected the older clinical tradition of viewing psychiatric conditions, once incurred, as life-long. However, those engaged in longitudinal studies quickly realized that lifetime questions hamstrung any analysis of change - respondents could never get better, they could only become invalid. In early studies, the time period specified for "current problems" varied, from 6 months in the Diagnostic Interview Schedule (DIS) to as long as 3 years (Cahalan \& Room, 1974). The literature has settled down to 12 months as the usual time period for "current" problems.

This often raises problems for analyses of the relation between drinking patterns and drinking problems, where it is usually desirable to have the two domains measured on the time period. To facilitate cross-analysis with "current problem" measures, present-day surveys usually include some items on drinking in the most recent 12 months.

Tables 5 and 6 illustrate efforts in more recent studies to measure social harm from both sides of the interaction. Table 5 shows a version of questions that have been asked 
Table 7

Items on social harm from others, 1989 Canadian national survey (Eliany et al., 1992)

"The next few questions are about your experience with other people's drinking problems. Have you ever... Was this during the past 12 months?"

a. been insulted or humiliated by someone who had been drinking?

b. had serious arguments or quarrels as a result of someone else's drinking?

c. had friendships break up as a result of someone else's drinking?

d. had family problems or marriage difficulties due to someone else's drinking?

e. been a passenger with a driver who had too much to drink?

f. been in a motor vehicle accident because of someone else's drinking?

g. had your property vandalized by someone who had been drinking?

h. been pushed, hit or assaulted by someone who had been drinking?

i. been disturbed by loud parties or the behaviour of people drinking?

j. had financial trouble because of someone else's drinking?

in several surveys in the US and Canada (e.g., Room, Greenfield, \& Weisner, 1991) in the perspective of social control efforts: how many people and in what relation have said something to the respondent about his/her drinking, and how many people and in which relation has the respondent said something to about their drinking? The frame has thus been more in terms of social-control efforts concerning drinking (Holmila, 1987) than in terms of measuring social harm. It is clear, however, that such an approach could be adapted to the social harm agenda.

Table 6 measures a different kind of interactional problem — in the context here of criminal behaviours - from both sides of the interaction (Scott, Schafer, \& Greenfield, 1999). Respondents were asked both about their own drinking and about the drinking of the other in the criminal event, and about events in which they defined themselves as the perpetrator and also events where they defined themselves as the victim.

Tables 7 and 8 show two series of items concerning impact on the respondent of others' intoxication of drinking problems (Eliany, Giesbrecht, Nelson, Wellman, \& Wortley, 1992; Mäkelä et al., 1999). Although such series have a shorter history than the items concerning the drinker's own problems from drinking, their use appears to be spreading internationally.

Table 8

Items on social harm from others, Nordic survey (Mäkelä et al., 1999)

"During the past 12 months, has it ever happened that. ." — no; yes, once or twice; yes, several times.

58. You have been harassed or bothered by intoxicated people on the street or in some other public place

59. You have been harassed or bothered by intoxicated people at a party or some other private setting

60. An intoxicated person has harmed you physically

61. An intoxicated person has ruined your clothes or other belongings

62. You have been called names or otherwise insulted by intoxicated people

63. You have been afraid of intoxicated people you encountered on the street

64. You have been kept awake at night by drunken noises 


\section{Traditions of aggregation and analysis of drinking problems scores}

From the first, US general population surveys sought to aggregate drinking problems items into one or more summary scales. Mulford and Miller (1960), for instance, constructed one scale for "troubles due to drinking," and another on "preoccupation with alcohol"; in later work, Mulford came to see the latter as more or less an operational measure of alcoholism concepts. Genevieve Knupfer, trained both in psychiatry and in sociology, took a pragmatic and eclectic view of what should be measured under the rubric of "problem drinking" in the general population when she turned to this issue in the mid-1960s (Knupfer, 1967). Knupfer's approach was to identify different conceptual areas of "problems from drinking," and construct subscales in about a dozen areas. Table 2 shows an example of such subscales in the social harm area. A "serious problem," a "slight problem" and a "noproblem" level was defined in each problem area, either by decision a priori (e.g., job loss was defined as more serious than complaints at work), or by the number of positive responses given to items in the area.

Analysts in Knupfer's tradition differed somewhat in how the problem-area scores were presented in analysis. While Knupfer (1967) and Cahalan (1970) presented prevalence rates for the individual problem-area scores, their main attention tended to be on an "overall problems score" that added together scores from all the problem areas. Clark (1966), on the other hand, kept the problem-area scores separate, focussing on the extent of overlap between a positive score in one problem area and a positive score in another - an approach Room (1977) also applied to problems from opiate use. A third approach, used by Cahalan and Room (1974), used a typology distinguishing "tangible consequences" (combining social and health consequences) from binge drinking and other problematic consumption.

In later work in the same social epidemiological tradition, Hilton (1991) primarily analyzed drinking problems in terms of two domains, one identified as "dependence" and the other as "consequences." A similar division between "personal" and "social" consequences was used in analyzing a set of items in the WHO study of Community Response to Alcohol Problems (Rootman \& Moser, 1985).

Psychiatric epidemiology's entry in the alcohol epidemiology field affected summarizations of alcohol problems in a number of ways. In the first place, the tradition's orientation to psychiatric nosology meant that drinking-problem items were now primarily aggregated in terms of the dichotomy of "making" or "not making" a diagnosis for the particular respondent. Initially, the questionnaires and analyses were oriented to DSM-III, mostly reporting only a combined dichotomy of those qualifying or not qualifying for either alcohol dependence or abuse.

Currently, psychiatric epidemiological studies in the alcohol field usually measure whether a respondent qualifies for a diagnosis on four main diagnoses: "alcohol dependence" and "alcohol abuse" in DSM-IV, and "alcohol-dependence syndrome" and "harmful use of alcohol" in ICD-10. Since ICD-10 "harmful use" is supposed to include harm only to psychological or physical health, only DSM-IV "alcohol abuse" is unambiguously a measure of legal and other social consequences of drinking.

Given its orientation and epistemology, the psychiatric epidemiology tradition has been little interested in the issues of causal relationship and conceptual clusterings that have 
concerned the social epidemiological tradition of measuring alcohol problems. The focus has rather been on psychometric traditions of measurement and of establishing the scientific respectability of measures with test-retest reliability studies (Kirk \& Kutchins, 1992). Studies in both the social and the psychiatric traditions tended to find, in applying large assortments of "problem" items to a nonclinical population, a strong general factor emerged in principal components factor analysis. The psychiatric epidemiology tradition has tended to regard this as evidence for the validity of a single generalized dependence concept (e.g., Hasin, Muthén, Wisnicki, \& Grant, 1994). The social epidemiology tradition has tended to take a more limited view of the finding's significance, suspecting that the underlying commonality is simply a willingness to get quite drunk (or to acknowledge getting quite drunk).

The psychiatric epidemiology tradition, on the other hand, is having considerable trouble fitting the findings for "alcohol abuse" into its paradigm. Again, both traditions report the same findings: items from the abuse/harmful use area load into a single common factor with dependence items in factor analyses (e.g., Hasin et al., 1994), but the commonality among items tends to be least for indicators of social reactions and other problems related to drinking. From the point of view of psychiatric epidemiology's psychometric traditions, this has led to questioning of the diagnostic viability of a separate arena of harmful use or abuse (i.e., tangible consequences of drinking).

However, the fact that two items do not have a strong positive correlation does not indicate much about their conceptual relationship. If they are conceptualized as alternative manifestations of the same phenomenon, they might even have a strong negative correlation, and still belong in the same measure. There is a need to pay attention to concepts as well as factor analysis results in constructing measures of social harm from drinking.

In recent years, a further tradition of brief screening instruments has strengthened its position in the field of drinking problems measurement. Given its pragmatic purposes, a screening instrument makes no claims to be measuring diagnoses, or about the conceptual status of its component items. The criterion for including items in a screening instrument are firstly the extent to which, as scored together, they approximate an underlying condition that is of clinical interest, and secondly, that "false negatives" be kept to a minimum. Screening measures thus often combine items across a range of conceptual domains, frequently asked on a lifetime basis. The two screening measures that are probably now most widely used in population surveys, CAGE and AUDIT, both include items on drinking behaviours, on cognitions about drinking, and on the reactions of others. Responses across these different domains are simply summed to yield an overall score on the measure (Allen \& Colombus, 1995).

\section{Issues in measuring social harm}

\subsection{Attribution and causation}

There is a long tradition in the alcohol literature of worrying about what is meant by calling something an "alcohol-related problem" (e.g., Levine, 1984). The general medical epidemiological literature adopts an approach that differs fundamentally from the approach of the traditions considered in this paper. The attribution of causation is made at an aggregate level, in 
terms of probabilities, and is made by the analyst. The causal attribution often comes in the form of an "attributable fraction" of some condition or problem, the proportion of the problem that would not have occurred in the absence of the drinking. The attributable fraction may be based on a formal meta-analysis of the available peer-reviewed studies (English et al., 1995).

There are serious questions about the application of such methods even to such problems as chronic health conditions. The evidence that all of the connection measured is causal rather than associational is often rather weak. The analyses usually assume that the true relationship between level of alcohol consumption and the problem will be the same everywhere. These assumptions become particularly problematic if they are applied to the terrain of social harm. The extent of social problems from a given amount of drinking will vary with the place of drinking in the culture (Cahalan \& Room, 1974). The epidemiological studies also typically measure only the individual-level harm to the drinker, and thus miss harm to others and harm at aggregate levels (Room \& Rossow, 2000).

On the other hand, the traditions of research considered here primarily rely on the respondent to make an attribution (Edwards et al., 1994, pp. 48-50). Thus the causal connection is often built into the question a priori. Other questions do not, on their face, involve a causal link to a problem: for an item like "I find I have to drink more now to get the same effect as before," the problematization comes from the researcher's interpretation of the behaviour. However, this interpretation does reflect general clinical and cultural interpretations, so that the respondent, too, may recognize that the answer being given will be seen as signalling a problem.

When and how well a respondent's attribution maps onto a causal relationship is obviously a thorny question. Presumably, there are respondents who will maintain a firm position that any calamities that befell them have nothing to do with their drinking, even if others have said otherwise to them. On the other hand, there is some evidence that, at least for responses on harm to one's health from drinking, some positive responses reflect vague fears rather than a concrete condition and connection (Greenfield \& Rogers, 1997).

There is a considerable range in the formulations of the items in Tables 1-8 concerning how far and in what way the respondent is being asked to go beyond the simple connection with drinking.

1. Sometimes the respondent is simply asked to report a temporal association, with no necessary attribution of cause (e.g., Table 4, item 21: "Get into physical fights while drinking or right after drinking").

2. Sometimes a weak causal attribution is asked for (e.g., Table 2, item 15: "My drinking was involved in my losing a friendship or drifting apart from a friend").

3. Often the causal attribution asked for is strong (e.g., Table 3, item 46: "I have lost a friend because of my drinking").

Other dimensions of variation include:

(a) whether a specific event is being asked about, or the respondent is instead asked to make a global judgement (e.g., Table 2, item 42d: “...you felt your drinking had a harmful effect on your marriage or home life"); 
(b) whether there is any specification of what is meant by "drinking": (e.g., Table 3, item 9: "I have driven a motor vehicle after having three or more drinks"; Table 8, item 60: "An intoxicated person has harmed you physically");

(c) whether or not the item builds in the assumption that an event asked about is inherently a problem (e.g., Table 3, item 7: "My ability to be a good parent has been harmed by my drinking," vs. Table 2, item 10: "stayed away from work because of a hangover").

(d) who is making the attribution. In an item like "Neighbors indicated I should cut down on drinking" (Table 2, item 16), it is actually the neighbors who are defining the drinking as problematic. However, the respondent's cognition is also involved: she/he is at least admitting knowledge that someone else saw the drinking as problematic.

(e) whether the respondent's own mind-set is built into the item, in addition to attribution by others. Items in the psychiatric epidemiology tradition frequently focus on the respondent's own cognition in addition to other's attributions (e.g., Table 4, item 20: "Continue to drink even though you knew it was causing you trouble with your family or friends"). One of the items in the CAGE screening measure even builds in a conflict between the cognition of the respondent and of the others: "Have people annoyed you by criticizing your drinking?"

While those who have been involved in developing questionnaires have undertaken a good deal of pretesting and informal item analysis, there is rather little published literature discussing the relative merits of various ways of formulating the connection between the drinking and the event or problem, and testing empirically how much difference is made by differences in formulation. It must be expected that the different formulations will give very different results. In Cherpitel's (1996) analysis of emergency-room injury patients in California and Mississippi, patients were asked if they had had a drink in the $6 \mathrm{~h}$ before the injury event. Those who said "yes" were then asked whether they thought that the drinking had caused the injury. Of those with an injury from violence, $42 \%$ said "yes" to this, while $26 \%$ of those with injuries from other causes said "yes" (recalculated from Cherpitel's Table 4). Thus, a majority of those who might acknowledge being injured right after drinking declined to attribute the injury to the drinking.

The issue of causal attribution is bound to become even more complicated for crosscultural studies. Apart from linguistic variation in the nuances of such phrases as "due to" or "because of," and cultural differences in the propensity to attribute to drinking, there appear also to be cultural differences in general ideas about causation (Room et al., 1996).

\subsection{Systematizing the measurement of interaction problems with drinking}

The Knupfer (1967) tradition of measurement of drinking-related problems differentiated three dimensions: type of problem, severity, and recency or timing. We will not linger here on the recency or timing dimension; the battle against the older impulse to ask always in "lifetime" terms has largely been won. With respect to severity, some studies have asked for the number of times an item has been experienced in the reference period, but the most common approach in the literature has been simply an additive score of positive answers to items included in a domain or measure (in psychiatric epidemiology the scoring is often at the 
level of the "criterion" rather than the item - e.g., Woody, Cottler, \& Cacciola, 1993). The boundaries of the domain or measure are sometimes set on conceptual grounds, and sometimes determined by a factor or cluster analysis of a larger pool of items.

Knupfer took the view that not all items were of equal importance, and assigned differential weights to items according to her view of their face severity. Thus in her original schema losing a job because of drinking was given three points, whereas people at work commenting on the respondent's drinking was assigned one point. In an age of psychometric expectations, such a procedure has become hard to defend - although, of course, weighting all items equally is just as much a choice about the relative severity of items.

In terms of type of problems, Knupfer's (1967) original analysis included four indices falling in the area of social harm: trouble with spouse, trouble with friends, job trouble and police trouble. A later version in this tradition (Table 2) adds problems with relatives, plus two indices more on the periphery of social harm - belligerence and financial problems.

Knupfer's four indices more or less correspond to the three "social" harm dimensions employment/support status; legal status; family/social relationships — in a widely used clinical measure, the Addiction Severity Index (NIAAA Treatment Handbook, 1995). (However, it should be kept in mind that there is no alcohol attribution in most of the ASI items.)

If one examines the content of the items under these rubrics in Table 2, and similar items in the other tables, it can be seen that the items fall into several distinct types.

1. Concrete actions by others reportedly in response to the respondent's drinking: e.g., wife left because of your drinking; arrested for driving after drinking. Here the respondent is implicitly or explicitly stating that the motivation given for the other's action was something about the respondent's drinking.

2. Indications of verbal responses to or attempts to control the respondent's drinking: "some other relative said anything to you about your drinking or suggested that you cut down"; "a policeman questioned or warned me about my drinking." Other items have asked about others "getting angry" or finding the drinking "very displeasing"; Knupfer treated this as one step more serious than the verbal responses.

3. Global attribution by the respondent of harm in a life area: e.g., the commonly used "life-areas harm" series: "...felt your alcohol use had a harmful effect on your friendships and social life," etc. (Bondy \& Lange, 2000; Rehm, Frick, \& Bondy, 1999)

4. Items describing the respondent's behaviour while drinking that refer to a behaviour generally seen as problematic: e.g., "have gotten high or tight while on the job"; "while drinking, I have said harsh or cruel things to someone." The "belligerence" items in Table 2 might also be viewed in this frame.

All of these types of items could be asked for each of the four main life areas we have been considering (spouse and family; friends and sociable relations; work and school; police and lawfulness), although pretesting might show that a global attribution for the police/law area would be problematic. However, no questionnaire to my knowledge asks all four types of items systematically across the different life areas. 
Building an item pool on a systematic basis such as this could be regarded as a contribution towards a balanced and inclusive overall score on social consequences of drinking for the respondent. It would also create an opportunity for a number of interesting item-level analyses. In any given life area, for instance, what is the relation between problematic drinking behaviours and the extent of others' reaction, and what are contingencies affecting this relationship? What about the relation between the number and severity of reactions from others and the respondent's global evaluation of drinking's harm to that area of life - and what are the contingencies of this relationship? Are the relationships found in one life - area parallel to or different from those found in another life-area? Such a program of analysis would take the interactional nature of social harms from drinking seriously, and turn this into an agenda for research rather than simply the occasion for embarrassingly small kappa statistics.

Besides the option of summarizing by problem area, in the Knupfer tradition, it would also be possible to summarize by type of problem item (others' reactions, global self-assessment of harm, problematic behaviours, etc.), taking together similarly framed items across life areas. For the self-attributed "life-area harm" series, in fact, this approach has already been taken, since these items have commonly been used as a minimum series of items on harm (Rehm et al., 1999). (However, scales based on these items have usually included "harm to health" along with the social harm items, though this item is the most problematic in a general population survey context - Greenfield \& Rogers, 1997.) It would be interesting to analyze the interactions between these kinds of summary scales, particularly in the context of measures of the respondent's social margin and social position.

\subsection{Asking about the impact of others' drinking}

Relatively few attempts have been made to frame social harm items so they can be asked both of the drinker and of those around the drinker. As noted above, the small tradition of studies of social pressures concerning drinking on and from family and friends has done this (Table 5), primarily in the context of analyses of social control and of paths to treatment (e.g., Room, 1996b). At least one US study asks criminal behaviour and victimization items, and their relationship to drinking, in a common frame (Table 6; Scott et al., 1999), although the correspondence is not complete. In this particular series, the drinking of both parties to the interaction is asked about, which is rare elsewhere. It would be worthwhile, in my view, to pursue the kinds of approach taken in this study further.

A small tradition of analyses of the impact of others' drinking on the respondent began with an analysis by Fillmore (1985). Tables 7 and 8 show two more recent lists of such items. It is interesting to compare these items with the items asking about harm from the respondent's own drinking. The causal attribution to drinking in the "victim" items is generally very loose: the formulations are in terms of "someone who had been drinking" or "intoxicated people," not "due to someone's drinking." The focus is usually explicitly on concrete events, whereas items in own-drinking problem series often concern conditions, or are commonly interpreted as indicators of a condition. In addition, the items obviously reflect a range of seriousness, leading Fillmore (1985) to sort them into subcategories (obnoxious behavior, property damage, family and friend problems, violence, accidents, employment threatened). 
Analyses of items in this tradition have mostly been descriptive, and very often have stayed at the item level. Generally, those most likely to be victimized are those also reporting problems from their own drinking, i.e., those most at risk of victimizing others. In this light, it makes a great deal of sense to move towards measuring social harm from drinking from both sides at once - both from the perspective of the drinker, and from the perspective of those around the drinker.

The issue of when and how attributions are made is even more acute as a research question for attributions to others' than for attributions to one's own behaviour. In the US national victimization surveys, about $30 \%$ of the victims of personal crimes answer that they do not know whether the offender had been drinking or using drugs (Greenfeld, 1998). Questions in these traditions have so far mostly been limited to the dichotomy of whether the other "had been drinking" or not, and we know little about whether and how often survey respondents can give a more nuanced picture of the other's drinking.

\section{Conclusions}

(1) Social harm from drinking has an inherently interactional character: there is a behaviour defined as problematic, but there is also someone whom the behaviour impinges upon. The attribution to drinking often also has an interactional flavour: the drinker's own attribution may be the result of someone else's attribution, or a dispute concerning the attribution may become part of the problem. This means that the terrain of social harm from drinking will always be unfriendly territory for those with positivist hankerings for problems-as-absolutes. A marital conflict can never be defined as cleanly and so clearly as a property of one individual as can, for instance, a death from cirrhosis.

(2) The terrain of attribution to drinking needs to be turned into a topic for research. When and under what circumstances are which kinds of respondents willing to apply a particular attributional formulation? What are the empirical relationships, under varying circumstances, between application of one formulation and application of another? Answering these questions, of course, will require asking about problems in the marriage or at work, etc., in general, without any alcohol attribution. In my view, for many analytic purposes there is no escaping formulations in such terms as "because of drinking," but we need to understand better when they are applied and when not.

(3) Good measures of social harm from drinking need to be developed and validated, in the context of the measurement of drinking problems more generally. The measurement of drinking problems is currently in a confused state. On one side of the literature, the development in psychiatric epidemiology has culminated in very lengthy sets of questions, designed to map as exactly as possible the DSM-IV and ICD-10 diagnostic criteria and specifications. However, instruments like AUDADIS (Stinson et al., 1998) are beyond the scope of a multipurpose or monitoring survey, and are not well oriented to measuring social harm from drinking.

At another boundary of the literature is the kind of analysis represented by studies by Mäkelä and Mustonen (1988), in which the relation to drinking level of each of a number of drinking problem items is analyzed separately, with no aggregation at all. Such an analysis 
avoids entering the psychometric entanglements of aggregating across drinking problems. It also has the advantage of greater relevance to contextual and environmental approaches to preventing drinking problems, since contextual and environmental issues tend to vary from one kind of problem to another. However, the strategy simply avoids the policy-relevant question of summary measures of social harm.

A third direction in the literature is the search for relatively limited lists of items that can measure a fair representation of alcohol problems, and usable summary measures, in multiplepurpose questionnaires. A common recourse for this purpose at the moment is a screening measure such as the AUDIT (Allen \& Colombus, 1995), which has the advantage of a considerable track record of use and of psychometric testing.

However, if the study's purposes include a better understanding of interactions - for instance, of the relation between drinking patterns and alcohol-related problems - a measure like the AUDIT, which reaches across these dimensions, will not serve. Here what are needed are usable measures with a clear separation of domains of meaning. At a minimum, there is a need to return to a separation between drinking behaviour, cognitions about drinking, and adverse consequences of drinking.

Along with developing defensible summary measures of social harm from drinking, work is also needed on building and testing new measures in each specific area of tangible consequences of drinking. An area that needs particular attention is family, relationship and other interactional problems. This area bulks large in social concerns about drinking, but we have almost no alcohol-specific social statistics for this area, and monitoring population levels and trends in problems in this area will depend on developing adequate survey measurements.

The terrain of social harm from drinking needs to be partitioned not only in terms of types of problems (such as the life areas/major social roles types) but also in terms of types of questions asked about each type of problem (others' reactions, self-attribution, problematic behaviour in the role, etc.). With development of a systematic set of questions covering these two dimensions, there will be considerable opportunity for item analyses that address substantive as well as methodological issues.

The dimensions of severity of problem and timing or recency of problem must also be taken into account. It is high time, also, to be thinking of approaches to assigning costs to different elements of social harm, perhaps including asking respondents about "willingnessto-pay" choices.

(4) The traditions of asking the drinker about problems from his/her own drinking and of asking "victims" about the effects of others' drinking need to be brought together into a common frame. Complicated as it may be, it is highly desirable to assess the drinking and drinking-relatedness of the behaviour of both sides in an interactional conflict or problem.

\section{Acknowledgments}

This paper is revised from a paper presented at a conference, "Measuring Drinking Patterns, Alcohol Problems and Their Connection," Skarpö, Stockholm, Sweden, 3-7 April, 2000 , and parts of a paper, "Measuring drinking patterns and problems: the experience of the 
last half century," presented at the 25th Annual Alcohol Epidemiology Symposium, Kettil Bruun Society for Social and Epidemiological Research on Alcohol, Montreal, Canada, June 1999. Thanks are due to Deborah Dawson for helpful comments.

\section{References}

Allen, J. P., \& Colombus, M. (1995). Assessing alcohol problems: a guide for clinicians and researchers. Rockville, MD: National Institute on Alcohol Abuse and Alcoholism (NIH Publication 95-3745).

Bondy, S., Lange, P. (2000). Measuring alcohol-related harm: test-retest reliability of a popular measure. Substance Use and Misuse, 35, 1263-1275.

Cahalan, D. (1970). Problem drinkers. San Francisco: Jossey-Bass.

Cahalan, D., \& Room, R. (1974). Problem drinking among American men. New Brunswick, NJ: Rutgers Center of Alcohol Studies (Monograph No. 7).

Cherpitel, C. (1996). Drinking patterns and problems and drinking in the event: an analysis of injury by cause among casualty patients. Alcoholism: Clinical and Experimental Research, 20, 1130-1137.

Clark, W. (1966). Operational definition of drinking problems and associated prevalence rates. Quarterly Journal of Studies on Alcohol, 27, 648-668.

Edwards, G., Anderson, P., Babor, T. F., Casswell, C., Ferrence, R., Giesbrecht, N., Godfrey, C., Holder, H. D., Lemmens, P., Mäkelä, K., Midanik, L. T., Norström, T., Österberg, E., Romelsjö, A., Room, R., Simpura, J., \& Skog, O.-J. (1994). Alcohol policy and the public good. Oxford: Oxford Univ. Press.

Eliany, M., Giesbrecht, N., Nelson, M., Wellman, B., Wortley, S. (1992). Alcohol and other drug use by Canadians: a national alcohol and other drugs survey (1989). Technical Report. Cat. No. H39-251/1992E. Ottawa: Health Canada.

English, D. R., Holman, C. D. J., Milne, E., Winter, H. G., Hulse, G. K., Codde, J. P., Bower, C. I., Corti, B., de Klerk, N., Knuiman, M. W., Kurinczuk, J. J., Lewin, G. F., \& Ryan, G. A. (1995). The quantification of drug caused morbidity and mortality in Australia. Canberra: Australian Government Publishing Service (1995 edition, 2 vols.).

Fillmore, K. M. (1985). The social victims of drinking. British Journal Addiction, 80, 307-314.

Giancola, P. R., Zeichner, A., Yarnell, J. E., \& Dickson, K. E. (1996). Relation between executive cognitive functioning and the adverse social consequences of alcohol use in social drinkers. Alcoholism: Clinical and Experimental Research, 20, 1094-1098.

Greenfeld, L. A. (1998). Alcohol and crime: an analysis of national data on the prevalence of alcohol involvement in crime. Washington, DC: Bureau of Justice Statistics (April).

Greenfield, T. K., \& Rogers, J. D. (1997). What's in a problem? Type and seriousness of harmful effects of drinking on health. Working paper F405. Berkeley: Alcohol Research Group.

Hasin, D. B., Muthén, B., Wisnicki, K. S., \& Grant, B. (1994). Validity of the biaxial dependence concept: a test in the U.S. general population. Addiction, 89, 573-579.

Hilton, M. E. (1991). Demographic characteristics and the frequency of heavy drinking as predictors of selfreported drinking problems. In: W. B. Clark, \& M. E. Hilton (Eds.), Alcohol in America: drinking practices and problems (pp. 194-212). Helsinki: Albany: State University of New York Press.

Holmila, M. (1987). Wives, husbands, and alcohol. Helsinki: Finnish Foundation for Alcohol Studies.

Jellinek, E. M. (1946). Phases in the drinking history of alcoholics: analysis of a survey conducted by the official organ of Alcoholics Anonymous. Quarterly Journal of Studies on Alcohol, 7, 1-88.

Kirk, S. A., \& Kutchins, H. (1992). The selling of DSM: the rhetoric of science in psychiatry. Hawthorne, NY: Aldine de Gruyter.

Knupfer, G. (1967). The epidemiology of problem drinking. American Journal of Public Health, 57, 973-986.

Levine, H. G. (1984). What is an alcohol-related problem? (Or, what are people talking about when they refer to alcohol problems?). Journal of Drug Issues, 14, 45-60.

Mäkelä, K. (1981). Scandinavian drinking survey: construction of composite indices of drinking attitudes and 
personal experiences related to drinking. Oslo: National Institute for Alcohol Research (SIFA mimeograph No. 47).

Mäkelä, K., \& Mustonen, H. (1988). Positive and negative experiences related to drinking as a function of annual alcohol intake. British Journal of Addiction, 83, 403-408.

Mäkelä, P., Fonager, K., Hibell, B., Nordlund, S., Sabroe, S., \& Simpura, S. (1999). Drinking habits in the Nordic countries. Oslo: National Institute for Alcohol and Drug Research (SIFA Report No. 2/99).

Miller, W. R., Tonigan, J. S., \& Longabaugh, R. (1995). Drinker Inventory of Consequences (DrInC): an instrument for assessing adverse consequences of alcohol abuse: test manual. Project MATCH monograph series vol. 4. Rockville, MD: National Institute on Alcohol Abuse and Alcoholism.

Mulford, H. A., \& Miller, D. E. (1960). Drinking in Iowa: IV. Preoccupation with alcohol and definitions of alcohol, heavy drinking and trouble due to drinking. Quarterly Journal of Studies on Alcohol, 21, 279-291.

Rehm, J., Frick, U., \& Bondy, S. (1999). Reliability and validity analysis of an alcohol-related harm scale for surveys. Journal of Studies on Alcohol, 60, 203-208.

Room, R. (1977). Notes on the spectrum of opiate use. In: Rittenhouse, J. D. (Ed.), The Epidemiology of Heroin and Other Narcotics (pp. 40-50). DHEW Publication No. (ADM) 78-559. Washington: National Institute on Drug Abuse (Research Monograph No. 16).

Room, R. (1989a). Spouse reports vs. self reports of drinking in general population surveys, presented at the 15th Annual Alcohol Epidemiology Symposium, Kettil Bruun Society for Social and Epidemiological Research on Alcohol, Maastricht, Netherlands (June) (pp. 1-16). Berkeley, CA: Alcohol Research Group. Publication E268.

Room, R. (1989b). Worries, concerns, suggestions: informal processes in the social control of drinking, presented at the Annual Meeting of the Society for the Study of Social Problems, Oakland, California (pp. 1-14). Berkeley, CA: Alcohol Research Group. Publication E284.

Room, R. (1996a). Alcohol consumption and social harm: conceptual issues and historical perspectives. Contemporary Drug Problems, 23, 373-388.

Room, R. (1996b). Patterns of family responses to alcohol and tobacco problems. Drug and Alcohol Review, 15, $171-181$.

Room, R. (1998). Drinking patterns and alcohol-related social problems: frameworks for analysis in developing societies. Drug and Alcohol Review, 17, 389-398.

Room, R. (2000). Measuring drinking patterns: the experience of the last half century. Journal of Substance Abuse, $12,23-31$.

Room, R., Greenfield, T., \& Weisner, C. (1991). "People who might have liked you to drink less": changing responses to drinking by U.S. family members and friends, 1979-1990. Contemporary Drug Problems, 18, $573-595$.

Room, R., Janca, A., Bennett, L. A., Schmidt, L., Sartorius, N., et al (1996). WHO cross-cultural applicability research on diagnosis and assessment of substance use disorders: an overview of methods and selected results [with comments and a response]. Addiction, 91, 199-230.

Room, R., \& Rossow, I. (2000). The share of violence attributable to drinking: what do we know and what research is needed? In: Commissioned papers, alcohol policy XII conference: alcohol and crime: research and practice for prevention (pp. 41-54). Washington, DC: National Crime Prevention Council (June).

Rootman, I., \& Moser, J. (1985). Community response to alcohol-related problems. Washington, DC: USGPO.

Scott, K. D., Schafer, J., \& Greenfield, T. K. (1999). The role of alcohol in physical assault perpetration and victimization. Journal of Studies on Alcohol, 60, 528-536.

Stinson, F. S., Yi, H., Grant, B. F., Chou, P., Dawson, D., \& Pickering, R. (1998). Drinking in the United States: main findings from the 1992 National Longitudinal Alcohol Epidemiologic Survey (NLAES) (1st ed.), U.S. alcohol epidemiologic data reference manual, vol. 6. Bethesda, MD: National Institute on Alcohol Abuse and Alcoholism (November).

Straus, R., \& Bacon, S. D. (1953). Drinking in college. New Haven: Yale University Press.

Woody, G. E., Cottler, L. B., \& Cacciola, J. (1993). Severity of dependence: data from the DSM-IV field trials. Addiction, 88, 1573-1579. 